\title{
Storyboarding and suggestopedia for curriculum re-design
}

\author{
Isabel Lucas
}

University of Cumbria

\section{Amanda Chapman}

University of Cumbria

Keywords: curriculum design; storyboarding; course planning; Covid-19.

\section{The challenge}

Having successfully moved face-to-face teaching to the online environment in spring 2020, there arose a need to work with tutors to move them from 'mirroring' their classroom learning, teaching and assessment (LTA) practice (White, 2021) to re-designing their LTA practice online for at least a full semester. For many tutors, the sudden move online had been overwhelming, but by summer 2020 , tutors were feeling more settled and accustomed to a new way of working. The challenge we faced was how to balance celebration of those early 'successes' in online delivery and the resultant increase in tutor confidence whilst supporting tutors in understanding that a new approach was now required. The emergency response had focused on logistics and what was possible at the time; we now needed to look at what works best for learners and the subject.

The aim of our project was, therefore, to move tutors away from their emergency LTA approach and practices. Free from the constraints of timetabling and prescribed contact hours, which had been the main drivers in relation to how teaching was organised preCovid, we wanted to support tutors in seeing beyond these constraints and understanding the possibilities for their curriculum and LTA when these design elements were no longer present. By carving out time and space in which they could reflect on their curriculum, we aimed to facilitate a stronger, connected curriculum at programme level by drawing on design principles for a distance-learning programme (Phipps and Merisotis, 2000). 
The driver behind our project was ultimately to instigate fundamental changes and instil creative thinking at the module level which could eventually lead to more sustained programme-level change across disciplines.

\section{The response}

At what was already an anxious time with high demands on tutors, it was clear that any development activity that would involve tutors questioning their existing design and delivery foundations needed to be non-threatening, supportive and reassuring. Ideally it would also be short, uplifting and empowering, recognising them as subject specialists. The idea of a creating a storyboard arose from the internally produced guidance for online delivery. In the guidance, we strongly suggested that course teams consider the use of narrative as a way of supporting students' ability to make connections across a module. There is evidence that building learning around a narrative, creating stories (Avraamidou and Goedhart, 2017) and using case studies can support memory recall (Rybarczyk, 2007; Vacek and Liesveld, 2020).

We experimented with creating our own version of how to build a narrative as a mode of delivery for the session, thus modelling the learning objectives of the session through the mode of delivery, and the session took tutors through the process of creating a storyboard for a module they teach. Tutors were asked to have blank paper and coloured pens for the session and to be somewhere quiet. After creating their storyboards, we asked them to send in photographs, and these were widely shared on a Padlet. We kept the activity lowtech so that tutors were not intimidated about engaging. Importantly, through tightly focused facilitation of the session, the participants were asked to both problematise and solve the issue of how best to deliver their module online. We hoped that this approach would give them a sense of ownership and that they would be inclined to take the outcome forward to move past the 'emergency' response towards a more considered approach.

Drawing on Lozanov's Suggestopedia approach (cited Richards and Rogers, 2001), the facilitators posed questions that supported participants in reflecting on and challenging their own assumptions regarding the most effective way to organise and assess their module. Each suggestive question ended with an instruction to draw the answer in their 
storyboard. Questions were delivered softly, with all participants on mute to create a relaxing atmosphere. Questions related back to previous ones, creating and suggesting their own narrative through forms that assumed good practice in curriculum design: 'Now, take a look again at .... How could they be broken down? Do that now in a different colour [pause]. Look again, how do the broken-down themes connect to each other? Why do you think that? Draw the connections on your storyboard'.

Participants were also asked to chunk their modules into ways that made sense for their subject, then consider and challenge the order on their storyboard. There were two main objectives behind the questioning technique used in the session: to encourage different ways of looking at the module and its delivery, and to encourage participants to create a connected curriculum. In addition to this, we hoped participants would find a 'golden thread' or narrative that would connect and align chunks, learning outcomes and the assessment (Biggs and Tang, 2011).

Following a successful pilot session with Law, the storyboarding session was rolled out across the university. The two facilitators noted that most participants, at some point, had a 'magic moment', a realisation about an unaligned assessment or ideas about a different order that could scaffold the learning more effectively. Feedback was wholly positive, attracting comments about the effectiveness of the technique in making what felt like an overwhelming task into a workable solution. One participant wrote that prior to the session they had felt they were working in 'a vacuum of ignorance' but afterwards, they felt they understood the full learner journey.

\section{Recommendations}

The immediate benefit of using storyboarding and Suggestopedia was that tutors were gently guided towards finding their own solutions to what seemed to them a 'wicked problem', that is, how to deliver a programme online that was designed to be delivered face-to-face with little knowledge of online learning or digital skills (Rittel and Webber 1973).

For those considering a similar project, we would recommend the following: 
- Ensure that participants have a shared experience to build on. Our participants understood what did not work from the emergency move online, and this meant they were motivated to develop their practice and had some knowledge and experience to use as a springboard for further development.

- Spend time creating an environment which is conducive to reflection in terms of the timing of the session and the choice of facilitator. Our Academic Development team are referred to and recognised as a 'trusted brand' and this encouraged participants to be open-minded about a new approach.

- Acknowledge that curriculum rules are understood differently by different people and subjects. A storyboarding process moves reflections on design away from teaching-led towards a learning-led approach. This means that participants make explicit links between design features that have previously not been considered. The result is a more connected curriculum and greater confidence among tutors in understanding the connections.

- Suggestopedia as an approach has the potential to bring calm to high-stress/highstakes situations, as it acknowledges expertise and helps participants to channel this.

- Take time to devise and test out the Suggestopedia approach questions; these should gently guide participants to 'notice' aspects of curriculum design, encourage them to challenge the status quo and test out a different approach. Ensure questions probe in sufficient depth. Deliver the questions gently and allow time for participants to think and draw before the next question.

- Offer a low-tech version so that participants are only dealing with one challenge at a time. Microsoft Teams was already familiar to our participants as a staff meeting platform, and the use of pen and paper meant their storyboards were personal to them, easy to create, and could be shared via a photo if appropriate.

The storyboarding approach has now been embedded into our Academic Development Curriculum Design days with programme teams and will remain a useful tool for tutors to re-use as they progress their blended approach to teaching and learning post-pandemic. 


\section{References}

Avraamidour, L. and Goedhart, M. (2017) 'Tell me a story: the use of narrative as a learning tool for natural selection', Educational Media International, 54(1), pp.20-33. Available at: https://doi.org/10.1080/09523987.2017.1324361 (Accessed: 5 October 2021).

Biggs, J. and Tang, C. (2011) Teaching for quality learning at university. $4^{\text {th }}$ edn. New York: McGraw Hill.

Phipps, R. and Merisotis, J. (2000) Quality on the line: benchmarks for success in internetbased distance education. Available at https://files.eric.ed.gov/fulltext/ED444407.pdf (Accessed: 8 June 2021).

Richards, J.C. and Rodgers, T.S. (2001) Approaches and methods in language teaching. Cambridge: Cambridge University Press.

Rittel, H.W.J. and Webber, M.M. (1973) 'Dilemmas in a general theory of planning', Policy Sciences, 4(2), pp.155-169. Available at: https://doi.org/10.1007/BF01405730 (Accessed: 11 October 2021)

Rybarczyk, B,J. (2007) 'Tools of engagement: using case studies in synchronous distancelearning environments', Journal of College Science Teaching, 37(1), pp.31-33.

Vacek, J. and Liesveld, J. (2020) 'Teaching concepts to nursing students using model case studies, the Venn diagram, and questioning strategies', Nursing Education Perspectives, 41(6), pp.373-375. Available at: $\underline{10.1097 / 01 . N E P .0000000000000514}$ (Accessed: 11 October 2021)

White, D., (2021) The need for presence not 'contact hours'. Available at: http://daveowhite.com/presence/ (Accessed: 8 June 2021). 


\section{Author details}

Isabel Lucas is the Head of Centre for Academic Practice Enhancement at the University of Cumbria, UK. She has taught in the UK and overseas for over 25 years, holds a number of external roles related to Learning, Teaching and Quality Enhancement, and is a Senior Fellow (AHE).

Amanda Chapman is a Senior Academic Developer in the Centre for Academic Practice Enhancement at the University of Cumbria, UK. She is Programme Leader for the PgCert Learning and Teaching in Higher Education and Scheme Lead for AdvanceHE Fellowships. 